\title{
THE POSSIBILITIES OF BIM QUALITY CONTROL IN THE GAME DEVELOPMENT ENVIRONMENT
}

\author{
T. Volarik ${ }^{1}$, M. Kuruc ${ }^{1}$, R. Kratochvíl ${ }^{1}$, O. Vystavěl ${ }^{1}$ \\ ${ }^{1}$ Institute of Geodesy, FCE BUT, Veveři 95, Brno, Czech Republic - (volarik.t, kuruc.m, richard.kratochvil, \\ ondrej.vystavel)@vutbr.cz
}

Commission V, WG V/7

KEY WORDS: heritage building information modelling (HBIM), laser scanning, quality control, as-built documentation, visualization.

\begin{abstract}
:
The quality control of the BIM model to be delivered is one of the most important steps in the process of information modelling. Quality control can take place on several levels. First of all, it is a control of geometric parameters, especially a control of the relative accuracy of the resulting model with respect to the modelled real object. Another type of quality control can be a check of the completeness of the model, whether the resulting model contains all the elements that are to be included in the model according to the requirements. MEP equipment such as fire extinguishers, for example, is a substantial content of BIM models. This may also be related to the required level of LOD, e.g. whether these elements are modelled with the required level of detail. Furthermore, the visual properties of the individual elements can be checked, for example whether the surface finish of the wall corresponds to reality. Subsequently, database and descriptive information of individual elements should be checked, such as technical parameters of various items of technical equipment of MEP content.

This article describes variants of the publication of a building information model for the purposes of BIM model quality control. The procedure of creating the final application in the game development environment Unreal Engine (Epic Games) is described on the example of a BIM model of a historical building from the middle of the 19th century.
\end{abstract}

\section{INTRODUCTION}

\subsection{An introduction to BIM quality and its control}

New requirements of quality control have come with the start of BIM style of modelling. Old traditional CAD design needed only graphical control. However, BIM style of modelling has come with a completely different type of work. The final model is not only about geometry but also about non-geometric information.

For a quick check of what to expect in a BIM model we can use Level of Development (LOD) which is used for description in which state the building is. There are six levels used.

For a further check of what to expect in a BIM model can be used two terms from the technical standard BS EN ISO 19650. These define Levels of definition (formerly known as levels of detail) which have two components:

- Level of Geometry (LOG) - graphical contents of model

- Level of Information (LOI) - non-graphical contents of model

Both of them are divided into categories, so called levels which describe how elaborated the elements in the model are. LOG and LOI are tightly connected because it makes more sense to have them on the same level. In the next picture we can see examples of usage of LOG with LOD together. However, it is again not necessary to have them on the same level but it is better.

\begin{tabular}{ccccc}
\hline pre design & $\begin{array}{c}\text { schematic } \\
\text { design } \\
\text { LOD 100 }\end{array}$ & $\begin{array}{c}\text { design } \\
\text { development } \\
\text { LOD 300 }\end{array}$ & $\begin{array}{c}\text { construction } \\
\text { stage } \\
\text { LOD 400 }\end{array}$ & $\begin{array}{c}\text { facility } \\
\text { management } \\
\text { LOD 500 }\end{array}$ \\
\hline LOG 100 & $\begin{array}{c}\text { LOG 200 } \\
\text { appropriate } \\
\text { geometry }\end{array}$ & $\begin{array}{c}\text { LOG 300 } \\
\text { precise } \\
\text { geometry }\end{array}$ & $\begin{array}{c}\text { LOG 400 } \\
\text { BIM uses } \\
\text { fabrication }\end{array}$ & LOG 500 \\
as-built & & &
\end{tabular}

Figure 1. LOD and LOG representation.

These levels are important for the investor because he defines what level is expected to be delivered. For investors it is very important to set an appropriate level which suits them the most. As it is mentioned in (Brumana, 2021) the definition of LOG and LOD are fundamental concepts introduced in the digitization process.

\subsection{The process of making a BIM model}

Making a BIM model is quite a complex procedure and lots of errors can occur on the way.

First of all, a geodetic network is made. Then ground control points are measured from geodetic points. Geodetic measurements can be in these days very precise and quality control of geodetic measurement is very well known and described.

The second act is mass collection of data. For this purpose there are used static laser scanners, mobile mapping devices or 
photogrammetry. The result is a point cloud. Quality control of a point cloud should be done via control points. It is necessary to have a representative quantum of control points which are spaced out equally throughout the whole object. This type of quality control is also well known and described.

The third part of work is BIM modelling. Firstly, we model the geometry of the object. Especially for as-built modelling of existing buildings it is essential to make some kind of generalisation. Historical buildings are even more difficult to model because of not being right-angular and often slightly damaged. Secondly, we add non-graphical contents to the model.

\section{RESEARCH BACKGROUND}

Banfi, F., 2021 writes about how to use BIM technology of modelling for existing historical buildings and how to use HBIM for Digital Cultural Heritage (DCH). A part of the paper describes the process now called scan-to-BIM. A need for DCH is explicitly stated in the conclusion: "The digital acceleration due to the pandemic has influenced the way we communicate and share information."

The COVID pandemic played a significant role in the creation of digital twins of historical monuments. The focus of the research in this paper is about moving with HBIM even more, more specifically into VR and AR. "Based on the research results reported in this study, it is possible to verify that virtual space offers a much stronger sense of presence than traditional forms of data sharing. With VR and AR, users feel closer and are in more direct contact with buildings".

Bagnolo, V. et al., 2021 proposes an HBIM workflow for reconstruction of 3D environments of historic buildings starting from laser scanning surveying approach." The final step is visualization in a game engine environment. "Game engines are used for the visualization of BIM models, as for the creation of virtual tours or for the enrichment of the information displayed through virtual or augmented reality." This statement is in full agreement with the latter paper from Mr. Banfi.

A very good opportunity for game engines in HBIM are for virtual tours.

Wang, J. et al., 2015 have developed a "prototype of real-time construction quality control". It consists of LiDAR and BIM real time systems. "The system can automatically collect onsite quality data, perform comparison between as-built point cloud data and an as-planned BIM model, and assess construction quality. With this system, three benefits can be identified: safety, accessibility, efficiency." This system can be used on-site for real time controls of existing constructions.

Kivimäki, T. \& Heikkilä, R., 2015 writes about "project quality control, which enables real-time monitoring of project progress and quality“. The research is on examples of railway and road construction projects in Finland. The main result is that the speed of quality control was improved. "3D design surfaces were produced and stored on a central collaboration cloud system. All measurement devices used on the site were integrated to the collaboration cloud via internet connection".

\section{METHODOLOGY}

The authors are specifically focused on the as-built BIM models of historical buildings. Creation of the as-built BIM requires comprehensive geodata acquisition such as ground control points, point clouds as well as imagery. Consequently, the BIM modelling process is performed based on the 3D data. As-built $\mathrm{BIM}$ is site-specific, therefore the building elements have to be modelled based on real situations. This process has to follow particular quality measures such as geometric rightness, level of detail as well as correct function of the element in the BIM model.

Types of errors in the model

- Quantitative / qualitative (related to the level of LOD - whether it is an error or a degree of generalization).

Quantitative - e.g. incorrect dimensions of the element (dimension of the masonry, size of the opening, height of the room, etc.), number of heating fins, number of luminaires, size of the distribution box, height level of the washbasin, etc.

Qualitative - e.g. masonry specifications, plaster color / type, floor / floor covering type, luminaire type, heating type, physical properties of the material, incorrect type of element material (e.g. staircase material, railing material, handrail material...). missing elements - missing categories of elements (e.g. electrical switches, sockets,

\section{- Topological}

incorrect connection of adjoining structures (usually it is an incorrect technological procedure of work in the given software) - "gaps" may arise between elements (e.g. between masonry in individual floors, in connections of horizontal building structures to vertical, incorrect interconnection of individual layers of masonry, etc.

\section{- Degree of detail}

some building structures, especially for historic buildings, may be equipped with architectural elements that are difficult to model (e.g. rounding of the corner of the masonry in the door opening area, stucco on the facade in the window area, reinforcement of the masonry in the corners of the building, balustrades around the staircase, etc.), in the model, such elements can be either generalized or neglected / omitted in the case of modeled elements there may be different levels of detail (e.g. window elements can be modeled in detail - including sash hinges, fittings, etc., while other elements such as doors may lack projections and the surface structure of door frames).

\section{- Visual}

incorrect surface properties of the material, which are often visible only when rendering the model (glossy / matt surface of the floor mole, plaster structure, paint color, color shade of the cladding / material, etc.).

In the case of historic buildings, there is damage to the building due to time (fallen plaster, partially damaged / missing masonry, etc.

\section{- Visualization problems}

Each object is actually located in a specific environment (surrounding trees, surrounding buildings, terrain relief, hills / slopes in the surrounding area, orientation to the sides of the world), this is related to the type of sunlight / shading of the object, how light penetrates inside the object during the day etc. Usually, the object is not modeled with detailed modeling of the surrounding environment, which during visualizations causes 
unnatural scenes caused, for example, by the fact that light penetrates the model through a window that is actually shaded by trees, etc.

The errors naturally occur during the modelling phase. The errors can not be avoided, therefore a subsequent process of quality management has to be carried out. The authors suggest a process analog to a debugging process with respect to software development. Initially, the modelling of wall and floor structures takes place in BIM modelling. This stage is usually inclinable to produce topological errors in the BIM model. Accordingly, the debugging process should take place to resolve these errors before the next stage of modelling. BIM modelling software like Autodesk Revit does not allow users to move freely through the model. Hence, the game engines are designed to develop an application in which the users can interact with the BIM model arbitrarily. Thus, the debugging process and quality assurance could be efficiently carried out in a game engine environment. In the following section the authors describe quality assurance on the example of BIM of a historical building Hubertcentrum (City of Kroměříž, Czechia).

\section{QUALITY MANAGEMENT IN AS-BUILT DOCUMENTATION}

Recently, the authors have been working on as-built BIM documentation of historical buildings of former cowshed from 1850 known as Hubertcentrum (City of Kroměřǐž, Czechia). The comprehensive work in the site consists of 3D laser scanning, geodetic survey of ground control points, imagery as well as video footage acquisition. Afterwards, the BIM modelling has been provided. Nevertheless, this building has many specific building elements to be modelled with respect to BIM methodology. Therefore, the BIM model has been implemented into the application called BIMQC created by the authors in Unreal Engine to provide quality assurance. These elements are described below as well as potential errors of types described above.

An example of the resulting BIM model of the described building is shown in Figure 2.

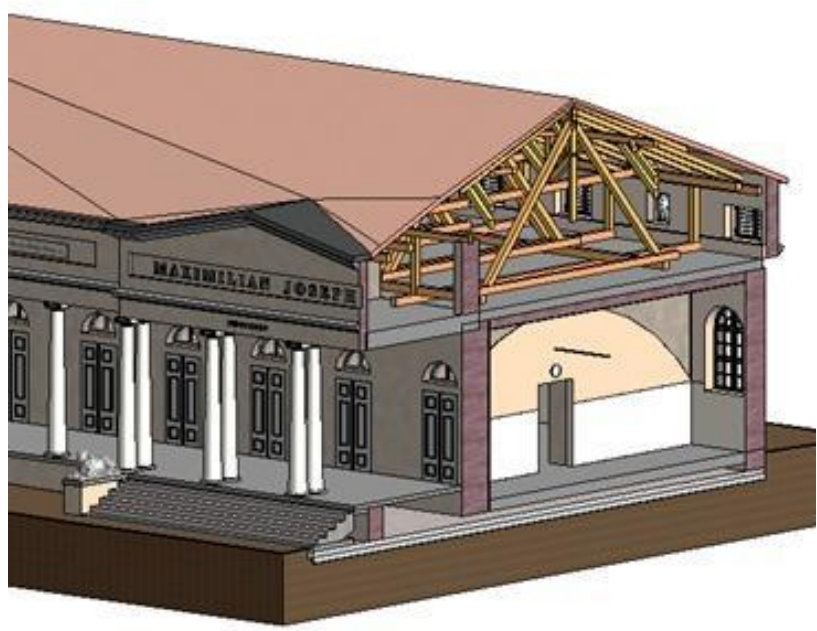

The following figures show examples of visualization of a modelled building in the environment of the Unreal Engine (Epic Games).

The roof construction has been refurbished in the past 10 years, therefore there are carpentry elements of two different phases (Fig. 3).

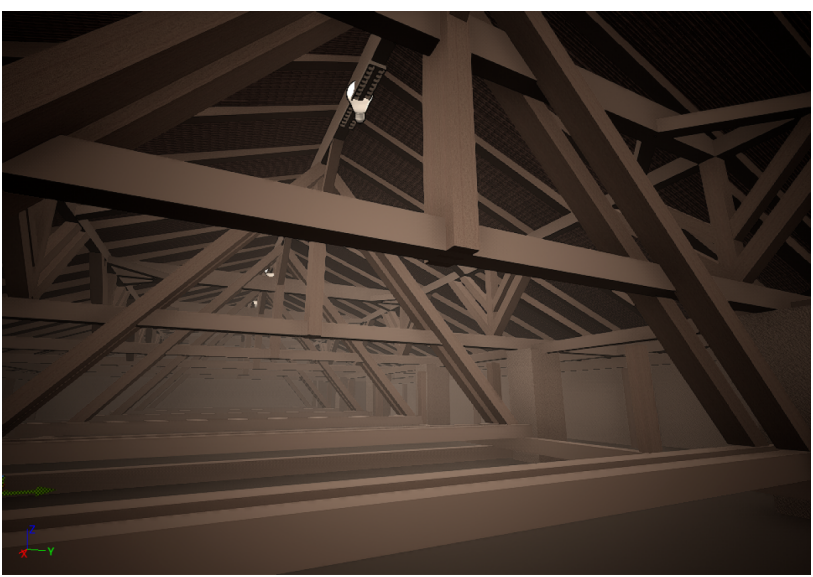

Figure 3. View of the roof construction.

Historic buildings offer a number of atypical building elements. The Hubertcentrum building was designed to be similar to Kačina Castle in the Empire style. The building contains a colonnade, a text inscription on the facade, a historical attic, cornices and other design elements.

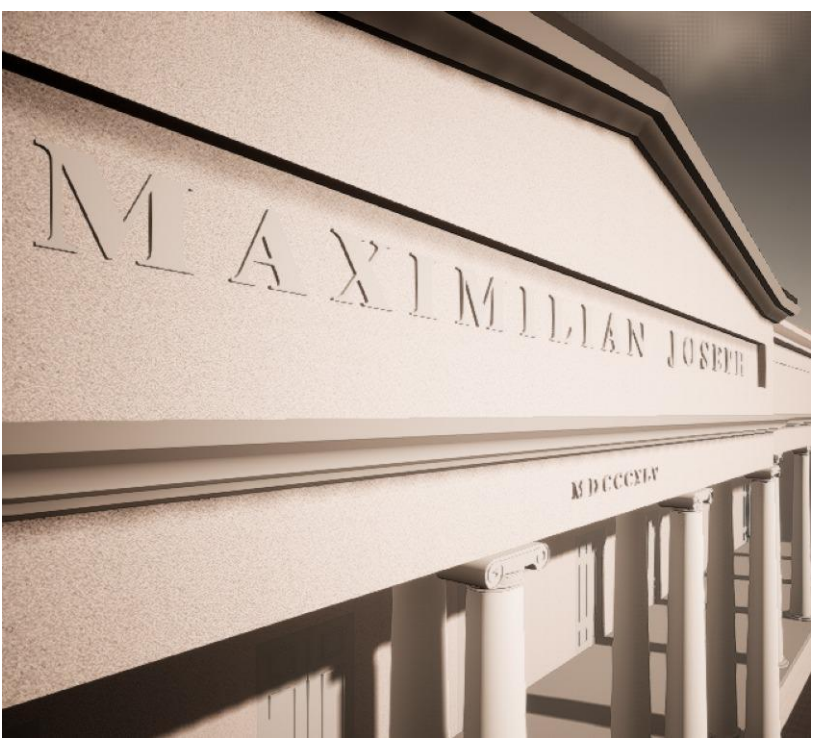

Figure 4. Example - text on the facade.

Another atypical element is the window shown in Figure 5. The lower part of which is provided with shutters on the outside, but in reality the window opening is only in the upper glazed part. Behind the shutters at the bottom of the window is solid masonry, these shutters are attached to the facade only as a design element.

Figure 2. View of resulting BIM model. 


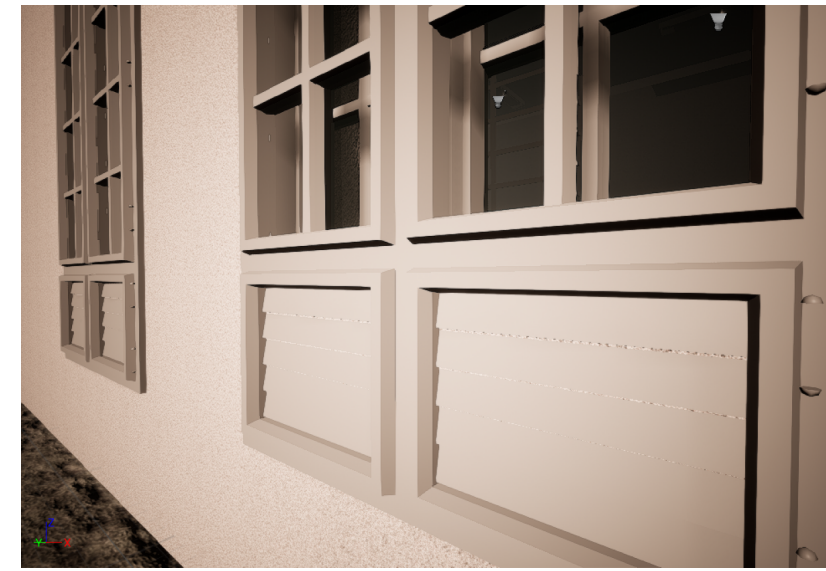

Figure 5. Example of atypical window.

The following figure shows the connection error of horizontal and vertical building structures that are not connected correctly. In the corner of the building, a space was created that is not filled with masonry. This is an example of a topological error wrong connection of masonry.

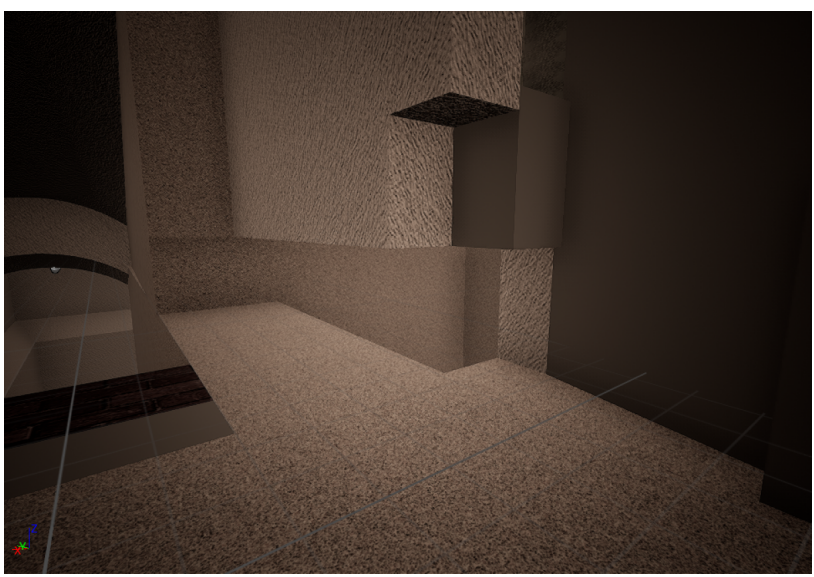

Figure 6. Example of error - missing part of masonry.

The built-in clock (Fig. 7) is modelled as a general Revit family model consisting of custom clock hands as well as specific font of clock dial. However, the material definition error occurs as the clock face is modelled transparent. The hands of the clock seem to levitate in the air.

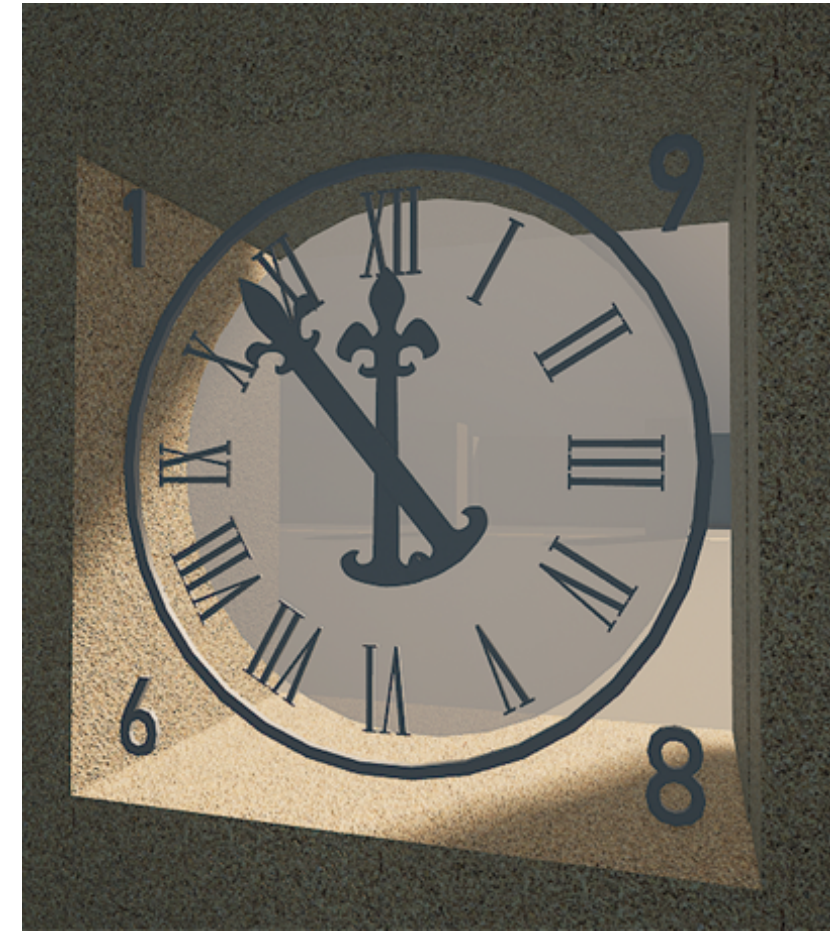

Figure 7. Built-in clock on facade.

\section{CONCLUSIONS}

The quality assurance process was tested on the example of the model of the historical building Hubertcentrum in the City of Kroměříz in Unreal Engine. The goal was to establish the quality assurance process of the resulting model without the need for professional CAD software (e.g. Autodesk Revit).

In the case of the Hubertcentrum building in the City of Kroměříž, the authors carried out a complete geodetic survey of the building in order to document the current state. The comprehensive work in the site consists of 3D laser scanning, geodetic survey of ground control points, imagery as well as video footage acquisition.

During the life cycle of a building, data management is performed by a number of users and professions, which do not always have the same hardware and software equipment as building designers.

A scene was created in the Unreal Engine environment, the basis of which was a model exported from Autodesk Revit. This scene can be exported as a standalone application, making it usable for many users as it does not require specific software.

The authors suggest considering the debugging phase of quality assurance of the BIM model. Therefore, the authors will focus on developing the BIMQC application with respect to the BIM model quality assurance in the modelling phases.

\section{REFERENCES}

Bagnolo, V. et al., 2021. BEYOND HBIM: SERIOUS GAMES AND PROCEDURAL MODELLING FOR HERITAGE DISSEMINATION. The International Archives of the Photogrammetry, Remote Sensing and Spatial Information 
Sciences, XLVI-4/W4-2021, pp.55-60. Available at: https://www.int-arch-photogramm-remote-sens-spatial-inf-sci.n et/XLVI-4-W4-2021/55/2021/.

Banfi, F., 2021. The Evolution of Interactivity, Immersion and Interoperability in HBIM: Digital Model Uses, VR and AR for Built Cultural Heritage. ISPRS International Journal of Geo-Information, 10(10). Available at: https://www.mdpi.com/2220-9964/10/10/685.

Brumana, R., Stanga, C. \& Banfi, F., 2021. Models and scales for quality control: toward the definition of specifications (GOA-LOG) for the generation and re-use of HBIM object libraries in a Common Data Environment. Applied Geomatics. Available

https://link.springer.com/10.1007/s12518-020-00351-2.

Kivimäki, T. \& Heikkilä, R., 2015. Infra BIM Based Real-Time Quality Control of Infrastructure Construction Projects. Proceedings of the 32nd ISARC, p.1-6. Available at: http://www.iaarc.org/publications/2015_proceedings_of_the_32 st_isarc_oulu_finland/infra_bim_based_real_time_quality_contr ol_of_infrastructure_construction_projects.html.

United-BIM Inc., 2020. 8 Crucial Mistakes in BIM Implementation and How to Tackle Them. United-BIM. Available

https://www.united-bim.com/8-crucial-mistakes-in-bim-implem entation-and-how-to-tackle-them/ [Accessed January 6, 2022].

Wang, J. et al., 2015. Integrating BIM and LiDAR for Real-Time Construction Quality Control. Journal of Intelligent \& Robotic Systems 79(3-4), pp.417-432. Available at: http://link.springer.com/10.1007/s10846-014-0116-8. 